\title{
Curd Coconut: Its Mystery and Potentialities (Review Article)
}

\author{
Narong Chomchalow ${ }^{1}$
}

\begin{abstract}
Curd coconut (CC) is a rare abnormality in the meat of the coconut which is thicker than normal and is fluffy and soft like curd. Being more delicious than normal coconut, $\mathrm{CC}$ is favored by people who eat it as dessert. In ten countries where CC occurs, its occurrence is at a very low frequency of about $0.15 \%$. CC is produced on a normal-looking palm which bears mostly normal fruits except for a very few CC fruits. Such fruit does not germinate, thus cannot be used to propagate the character. The experienced growers germinate normal-looking fruits obtained from the CC-bearing palm, which may or may not yield $\mathrm{CC}$ fruits after 8 years of planting. A controlled self-pollination of the CC-bearing palm yield a 3:1 ratio of normal: CC fruits, indicating the mother palm is a heterozygote (Kk) for the $\mathrm{CC}$ character, which is recessive (kk). The CC endosperm (kkk) cannot produce the enzyme galactomannanse to digest galactomannan to produce mannan. Thus, it contains galacto-mannanase that is viscous, but is not digested as food of the CC embryo. Consequently, it eventually dies. Galactomannan is responsible for the fluffy texture of the CC. CC embryo can be cultured in aseptic condition. Upon growing this cultured embryo to fruit-bearing stage, $\mathrm{CC}$ fruits are produced $100 \%$ if self pollinated. A hybridization scheme has been conducted by the Thailand Horticultural Research Institute. Pollen sources were from embryo-cultured palms while maternal parents were found dwarf cultivars, namely 'Nam Hom', 'Thung Khlet', Malayan Yellow Dwarf', and 'Malayan Red Dwarf'. The $\mathrm{F}_{1}$ hybrids were mostly semi-dwarf in stature (that is selfing in nature); they all produced $25 \% \mathrm{CC}$ fruits as expected. The most interesting cross was that with 'Nam Hom', in which $56 \%$ have aromatic water. It is postulated that if a backcross is made between semi-dwarf $F_{1}$ with the CC homozygous (kk) embryo-cultured palms, the resultant offspring would yield $50 \% \mathrm{CC}$ fruits which doubled that of the $\mathrm{F}_{2}$ which yield only $25 \%$ CC fruits. Not only CC fruits are delicious, they are also nutritious with higher amount of saturated and less unsaturated fatty acid than normal fruits. $\mathrm{CC}$ is always high on demand because people love to eat $\mathrm{CC}$ as dessert, even at the price ten times as much as ordinary coconut. CC growers earn 2.5 times as much compared to ordinary palms if they grow $F_{1}$ hybrids, but will double that amount if they make backcross by using pollens from homozygous embryo-cultured palms (kk).
\end{abstract}

Keywords: Galactomannan, heterozygote, embryo-cultured palms, dwarf cultivars, backcross.

\footnotetext{
${ }^{1}$ Chairman, Thailand Network for the Conservation and Enhancement of Landraces of Cultivated Plants (TNCEL), Thailand, and Chairman of the Conservation and Development of Coconut Oil of Thailand Forum (CDCOT), 770 Soi Paholyothin 32, Paholyothin Rd., Chatuchak, Bangkok, 10900 Thailand.

E-mail: narongchc@au.edu
} 


\section{Introduction}

Curd coconut (CC) is a rare abnormality in the meat of the coconut which is thicker than normal and is fluffy and soft like curd. Being more delicious than normal coconut, it is favored by people who eat it as desert. It is found in ten countries among more than 90 coconut-growing countries, namely Cambodia (called Dong Kathi), India (Thairu Tengai), Indonesia (Korpyor), Malaysia (Korpyor), Papua New Guinea (Niu Garuk), Philippines (Makapuno), Polynesia (Pia), Sri Lanka (Dikiri Pol), Thailand (Maphrao Kathi), and Vietnam (Dua Sap) (Chomchalow 2006).

It occurs sporadically in the coconut grove at a low frequency of $0.15 \%$. The grower knows exactly which palm would produce CC fruit and can pick the fruit from that particular palm with no mistake.

\section{The Mystery}

In the countries that $\mathrm{CC}$ occurs, its occurrence is at a very low frequency of about $0.15 \%$. It is produced on a normal-looking palm, known as 'occasional' CC-bearing palm, which bears mostly normal fruits except for a very few CC fruits. Since CC fruit does not germinate, it cannot be used to propagate the character. In order to propagate the CC-bearing palm, he experienced growers germinate normal - looking fruits obtained from the 'occasional' CC-bearing palm, which may or May not yield CC fruits after 8 years of planting (Chomchalow 1987).

\subsection{Unusual Mode of Inheritance}

$\mathrm{CC}$ is naturally borne on a normalappearing tall coconut palm where only a few fruits are $\mathrm{CC}$ while the majority is normal fruit. As the $\mathrm{CC}$ fruits do not germinate, propagation is traditionally done by germinating normal fruits from the CC-yielding palm, which may or may not yield CC fruits after eight years of planting.

\subsection{Is CC a Variety of the Coconut?}

There are two schools of thought:

\subsubsection{CC is not a variety of the coconut:}

This is evident from:

* CC fruit is borne on the same bunch with normal coconut.

* It occurs at low frequency and does not occur in every fruit of the same tree.

* It does not germinate, thus cannot reproduce itself.

* No true-breeding individual exists.

Some think that it is caused by a disease, but its causal organism is unknown. Perhaps it is caused by a virus or a mycoplasma. Some think that it is caused by a mineral deficiency, or by exposing to abnormal environment. But none has a definite evidence to prove its hypothesis.

\subsubsection{CC is a variety of the coconut:}

This is evident from:

* When a normal fruit from an $\mathrm{CC}$ fruit-bearing palm is planted, it sometimes yields $\mathrm{CC}$ fruits.

\subsection{Its Origin Was a Mystery}

Although the farmers know how to propagate $\mathrm{CC}$, but no one could explain its origin. It was believed that $\mathrm{CC}$ is borne on the eastern side of the palm, while others maintain that it is borne on the western side. Both are sometimes correct.

\section{Types of CC}

Based on the thickness and softness of the meat, and the amount and viscosity of the water in the fruit cavity, CC can be arbitrarily classified into the following categories:

Khao Chao CC (non-glutinous): Meat thickens a little with a little softness having a little viscous water.

Khao Niao CC (glutinous): Maximum thickness and softness of meat, and maximum water viscosity. 
There are, however, a graded series of Meat thickness and softness, and the amount and viscosity of the water (Figs. 1 and 2). Three factors are involved in the formation of fluffy meat and viscosity of the water. These are:

\subsection{The Age of the Fruit at Harvest:}

* If the fruit is harvest prematurely, the meat is still not fully developed into fluffy meat, while there is still a lot of notso-much viscous water in the fruit cavity. This type is the so-called, Khao Chao".

* If the fruits is harvested at a proper age, the meat tend to develop in full fluffy stage while only a little amount of viscous water remains in the fruit cavity. This is the so-called, "Khao Niao".

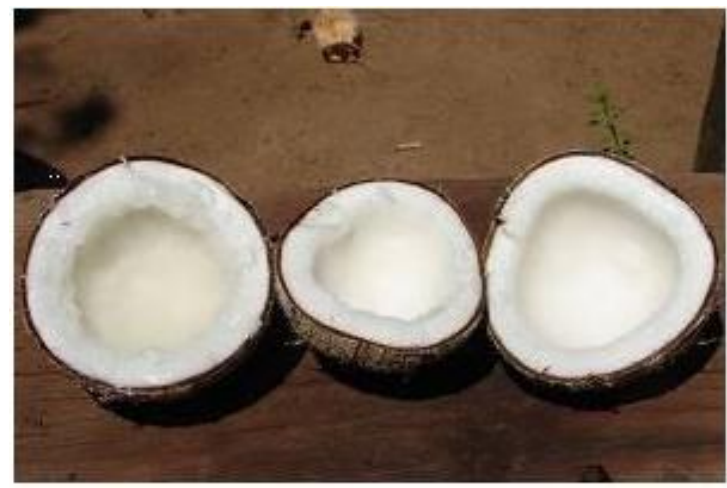

Figure 1. Three types of curd coconut varying in thickness of curd

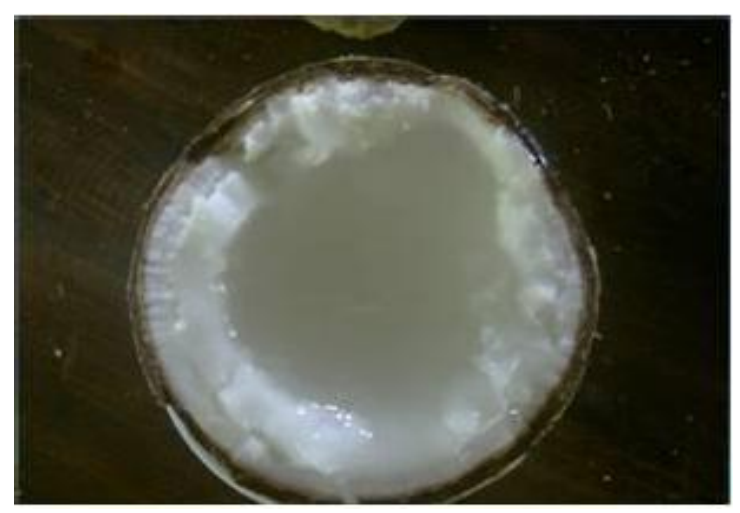

Figure 2. Maximum curd layer of curd coconut

\subsection{The Storage Period after Harvest:}

For prematurely-harvested fruit:

- If the fruit is kept for a short period of time, it still maintains the status of "Khao Chao".

- If the fruit is kept for a long period of time, it becomes "Khao Niao".

For fruit harvested at proper time:

- If the fruit is kept for a long short period of time, it is in the status of "Khao Niao".

- If the fruit is kept for a long period of time, all the fluffy meat disintegrates; this stage is called "Duean Kin" (moon eats).

\subsection{The Growing Condition:}

If the palm is grown in rather poor condition, the meat becomes less fluffy. It is of the type of "Khao Chao".

If the palm is grown in an optimum condition, the meat becomes fully fluffy. It is of the type of "Khao Niao".

\section{The Hypothesis on the Origin of CC}

\subsection{The Observation}

$\mathrm{CC}$ occurs in a particular coconut palm, and only in some fruits. Its cause is considered by some to be disease, but no causal organism found.

\subsection{The Experiment and Conclusion}

Controlled self-pollination of an CCproducing palm yields a 3:1 ratio of normal: CC progeny (Zuniga 1953). Thus it is concluded that $\mathrm{CC}$ character is controlled by a Single gene in which $\mathrm{CC}$ is recessive - k, and normal character is dominant - $\mathrm{K}$.

As the $\mathrm{CC}$ fruit (kk) cannot germinate, all CC-bearing palms are heterozygote (Kk). 


\section{Physiological Basis of CC}

\subsection{Why the Meat of CC is Fluffy?}

$\mathrm{CC}$ nuts have different cell wall materials and the component sugars of each fraction of the hydrolysis product varies between $\mathrm{CC}$ and normal nuts. Having three recessive genes (kkk), the CC endosperm may well be a case of cell dedifferentiation occurring on the plant itself (Kovoor 1981). Through cytochemical studies, Sebastian et al. (1987) was able to confirm that there were cellular cytochemical differences between the endosperm of normal and $\mathrm{CC}$ nuts. Such differences support the abnormal and tumour-like character of the CC cells. In addition, they were of opinion that an increasing concentration gradient of oil globules and protein bodies towards the testa suggests the early synthesis of these organelles during endosperm development.

\subsection{Why the CC Fruit Cannot Germinate?}

Chomchalow (2006) postulated that CC endosperm (kkk) cannot produce the enzyme galactomannanase to digest galactomannan to produce mannan. Thus, it contains galactomannan which is viscous, but is not a food $\mathrm{f}$ the $\mathrm{CC}$ embryo. Consequently, it dies eventually. Galactomannan is responsible for the fluffy texture of CC.

\section{Exploitation of the Knowledge \\ 6.1 Embryo Culture to Obtain Homozygous Line of $\mathrm{CC}$}

$\mathrm{CC}$ embryo can be cultured in aseptic condition until the plantlet is big enough to be transplanted in the nursery. Upon growing this cultured embryo to fruit bearing stage, and upon self-pollination, $\mathrm{CC}$ fruits are produced 100\% (de Guzman 1969).

Such a scheme has been adopted by the Uti Palmoil Seeds Co. Ltd., who grew 10,000 CC-embryo-cultured palms obtained from the farmers throughout the country on an isolated island in Vajiralongkorn Reservoir, Thong Pha Phum District, Kanchanaburi Province. About 2000 CC palms survived and all produced $100 \% \mathrm{CC}$ fruits as expected.

\subsection{Hybridization to Obtain Dwarf $F_{1}$ Palms for Commercial Production of $\mathrm{CC}$}

A hybridization scheme has been conducted by the Thailand Horticultural Research Institute (HRI). Pollen sources are from embryo-cultured CC palms while maternal parents are four dwarf cultivars, namely 'Nam Hom', 'Thung Khlet', 'Malayan Yellow Dwarf', and 'Malayan Red Dwarf'. The F1 hybrids are mostly semi-dwarf (which is selfpollinated in nature). They all produce $25 \%$ CC fruits as expected. Thmost interesting cross is that with 'Nam Hom' in which 56\% have aromatic water (Fig. 3) (Wattanayothin 2005)
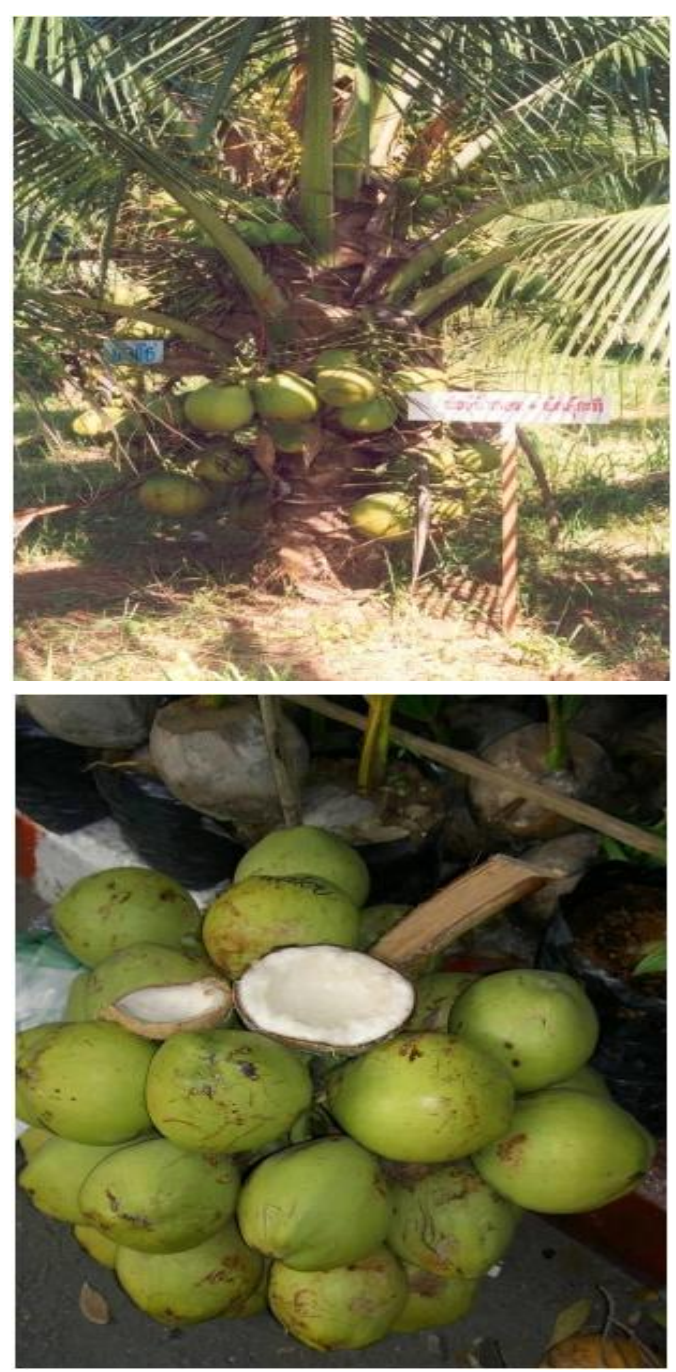

Figure 3. 'Aromatic' $x$ curd coconut hybrid 'Prolific bearing' curd coconut 


\subsection{Backcrossing F1 with Homozygous Line to Double the Amount of CC}

Chomchalow (2006) postulated that if a backcross is made between the semi-dwarf F1 with the $\mathrm{CC}$ homozygous embryo-cultured palms, the resultant offspring would yield 50\% $\mathrm{CC}$ fruits which doubled that of the $\mathrm{F} 2$ which yields only $25 \% \mathrm{CC}$ fruits.

\subsection{Natural Pollination of Dwarf Maternal Parents by Homozygous CC Palms}

Since production of F1 hybrids (in \# 6.2) is labor intensive, requiring emasculation of the Maternal parents as well as pollination with pollens obtained from collecting $\mathrm{CC}$ pollens by Climbing the tall palms, Charanasri (personal communication, 2013) is of opinion that it Would be more convenient and obtaining better result if selected dwarf palms were interplanted in the CC grove on the isolated island. When the dwarf palms tart to produce inflorescences, every one would be emasculated prior to pollen dehiscence in order to prevent them from pollinating the whole of $\mathrm{CC}$ plants on the island. Through natural pollination, the dwarf palms would be pollinated by pollens of CC palms resulting in production of $\mathrm{F} 1$ hybrids with much less effort in pollination. In this way, large amount of F1 hybrid seedlings could be produced for commercial planting, which is on high demand at present.

\section{Benefits of $\mathrm{CC}$}

\subsection{Nutritional Value of CC}

Not only CC fruits are delicious, they are also nutritious. Upon chemical analysis, CC has $93.3 \%$ saturated fatty acids (SFA) compared to normal palms of about $90 \%$ (Chomchalow 2006). It is now well known that SFA is health promotion, contradicting to the earlier belief that they cause heartdisease (Wickremasinghe 1994). It has also less unsaturated fatty acid, both mono (5.5\%), and poly $(0.8 \%)$, in contrast to normal palms which have about $10.3 \%$ mono- and $2.3 \%$ polyunsaturated fatty acids (Chomchalow
2006). It is now known that unsaturated fatty acids are hazardous to health, in contrast to earlier belief.

\subsection{Demand for CC}

$\mathrm{CC}$ is always high on demand because people love to eat $\mathrm{CC}$ as desert, even at the price ten times as much as ordinary coconut. CC can also be industrially processed into various food products including ice cream, pie, bottled or canned desert (Chomchalow 2006).

\subsection{Benefits to the Growers}

Assuming that a coconut palm yield 10 fruits per year (in reality, it is higher), a grower who grows F1 hybrid dwarf palms will obtain, through self-pollination, 75 normal fruits and 25 CC fruits (a 3:1 ratio). Based on the assumption that $\mathrm{CC}$ fruit fetches ten times as much as the ordinary fruit (Chomchalow 2006), CC grower earns $(1 \times 75)+(10 \times 25)=$ 325 units of money, while ordinary coconut grower earns $(1 \times 100)=100$ units of money (a unit is to the price per coconut fruit). Thus CC grower earns $325-100=225$ units or 2.25 times more if they grow F1 hybrids. But the income will double if he makes backcross of the F1 hybrid by using pollens from homozygous embryo-cultured CC palms to obtain a 1:1 ratio in the progeny, instead of a $3: 1$ ratio. By simple calculation, the income of $\mathrm{CC}$ grower would be $(10 \times 50)+(1 \times 50)=$ 550 units of money. This is $550-100=450$ units or 4.5 times more than that of ordinary coconut grower (of 100 units). Adding the fact that a hybrid normally yields $20 \%$ higher than the purebred, the income would be 540 units or 5.4 times higher.

\section{Epilogue}

The Thai Department of Agriculture is now able to produce 1,000 nuts per month of the F1 hybrids of the four crosses mentioned earlier (in \# 6.2) for sale to the farmers on a first-come-first serve basis at a very cheap price of Baht 30 (about 1 US \$) per seedlings. Within three years time, all these seedlings would bear fruits, one fourth of which will give 
$\mathrm{CC}$ nuts. Of the remaining three-fourths normal looking nuts, two parts are heterozygotes, and can be used as planting materials for the next generation. This is a special case of hybrids producing true to type hybrids for planting.

By the time these first lot of $\mathrm{CC}$ hybrid start to produce fruit, large amount of embryocultured palms would be grown. These would provide a good source of pollens to pollinate the F1 palms so that the progeny is expected to give a backcross ratio of $1: 1$, instead of an F2 ratio of $3: 1$. In such a case, half of the nuts is $\mathrm{CC}$ while the other half is heterozygous which can be used as planting material for the next generation. This has one distinct advantage; the farmer does not have to take one of three chances of planting a normal coconut, as all the normal-appearing nuts are heterozygotes!

As Thailand is the only country in the world that has 'Nam Hom' cultivar, the aromatic water - $\mathrm{CC}$ fruit is certainly a bonus in the $\mathrm{CC}$ palm production since it adds aroma to the already delicious fluffy meat.

It is hoped that within ten years, Thailand would become the world largest producer and exporter of CC coconut.

\section{References}

Charanasri, U. 2013. Personal Communication. Chomchalow, N. 1987. Maphrao Kathi (makapuno). Chaiyaphruek Witthayasat. 202: 6-9 (in Thai).

Chomchalow, N. 2006. Maphroa Kathi. Thailand Network for the Conservation and Enhancement of Landraces of Cultivated Plants (TNCEL), Bangkok, Thailand (in Thai).

de Guzman, E.V. 1969. The growth and development of coconut 'makapuno' embryo in vitro. 1 . The induction of ooting. Philippine Agriculturist 53(2): 6578.
Kovoor, A. 1981. Palm tissue culture: state of the art and its application to the coconut. Technical Working Party on Coconut Production, Protection and Processing, Session 5, Manila, The Philippines, 3 December 1979. FAO Plant Production and Protection Paper No. 30. Plant Production and Protection Division, Food and Agriculture Organization (FAO) of the United Nations (UN), Rome, Italy.

Sebastian, L.C.; Mujer, C.U.; and Mendoza, E.M.T. $1987 . \quad$ A comparative cytochemical study on mature makapuno and normal coconut endosperm. Philippine Journal of Coconut Studies 12(1): 14-22.

Watanayothin, S. 2005. The study on curd coconut hybrids. Journal of TNCEL 1(3): 6-7 (in Thai).

Wickremasinghe, R.L. 1994. Coconut oil, not the villain. Cocoinfo International 1(2): 6-7.

Zuniga, L.C. 1953. The probable inheritance of the makapuno character of the coconut. Philippine Agriculturist 36: 40213. 